\title{
A Review of Different Configurations and Control Techniques for DSTATCOM in the Distribution system
}

\author{
Khammampati $R$ Sree Jyothi ${ }^{*}$, Dr. P. Venkatesh $\mathrm{Kumar}^{2}$, Dr. J. JayaKumar ${ }^{3}$ \\ ${ }^{1}$ Research scholar,EEE Department,Karunya Institute of Technology and Sciences,Coimbatore,India \\ ${ }^{2}$ Assistant Professor,EEE Department,Karunya Institute of Technology and Sciences, Coimbatore,India \\ ${ }^{3}$ Professor,EEE Department,Karunya Institute of Technology and Sciences, Coimbatore,India
}

\begin{abstract}
This paper presents a review of DSTATCOM Topologies and power quality control Techniques. The used topologies are Three-phase Three-wire and Three-phase four-wire and control techniques are Instantaneous reactive power theory(IRP), Synchronous Reference Frame Theory(SRF), Model Predictive Control (MPC), Sliding mode control(SMC), Adaptive Neuro-fuzzy interface systems(ANFIS) and Artificial intelligence based controllers. These control techniques are used to mitigate the reactive power compensation, load balancing, Neutral current compensation, harmonics reduction and maintains the Total harmonic Distortion in IEEE519 standards. Performance investigated in Single-phase Distribution systems by connecting with STATCOM and without DSTATCOM in MATLAB/SIMULINK.
\end{abstract}

Keywords: DSTATCOM, IRP Theory, SRF theory, MPC, SMC, and ANFIS control Technique

\section{INTRODUCTION}

All electrical types of equipment suffer from power quality issues when connected to a distribution system. So this leads to currents distortion and voltage unbalance resulting in poor performance of the equipment and power losses. Due to rapid growth in the usage of electrical power in distribution, the conventional strategies offer degraded performance, which gave the direction for better-compensated strategies. Distribution Static Synchronous Compensator (DSTATCOM) is dynamically implemented to improve the power quality (PQ) problems. Among all controllers, the Distribution compensator is the most effective and powerful device to tackle the issues related to power quality. This paper discusses the various control methods required to improve power quality. [1]

DSTATCOM mainly consists of three main parts, those are Voltage source converter (VSC), a set of coupling reactors and a controller. The basic principle of a DSTATCOM in a power system is the generation of a controllable $\mathrm{AC}$ voltage source by a Voltage source inverter connected to a dc capacitor. The AC voltage source appears behind a transformer leakage reactance. The DSTATCOM is caused by the voltage difference across this reactance, which transfers the active and reactive power between the power systems. The DSTATCOM has connected to the power system networks wherein voltage quality problem is a major concern.[2]

There are two main control techniques implemented in the DSTATCOM. One is the AC voltage regulation of the power system at the bus where the DSTATCOM is connected. And the second one is dc voltage control connected across the capacitor inside the DSTATCOM. It is well known that shunt reactive power injection may be used to control the bus voltage. In the simple strategy, both the regulators are proportional-integral (PI) type controllers. The control algorithms are obtainable for at most generations of reference sources current designed for the control of VSC based DSTATCOM is Instantaneous reactive power theory (IRP), Synchronous Reference frame theory(SRF), Sliding mode controller(SMC), Model predictive controller(MPC) and Adaptive Neuro-fuzzy inference system(ANFIS).[3]

\section{DSTATCOM TOPOLOGY}

The DSTATCOM Topologies can be classified based on the number of switching devices, use of transformers for isolation, use of transformers for neutral current compensation, etc. These DSTATCOMs are developed to meet the requirements of multiple applications such as three-phase three-wire and three-phase four-wire distribution systems.[4]

\subsection{Three-Phase Three-Wire DSTATCOM}

The Three-phase Three-wire distribution system is used for the compensation of consumer loads and also 
improves the power quality of the system. The regulation and control of equal dc bus voltages and dc capacitors are quite high. The topology based on the three-phase threewire with a capacitor is advantageous due to the use of fewer switching devices and this topology is shown in Fig. The figure represents the three-phase voltages $\mathrm{Vsa}, \mathrm{Vsb}$, and Vsc and corresponding currents isa,isb and isc connected to Nonlinear unbalanced load.[5]

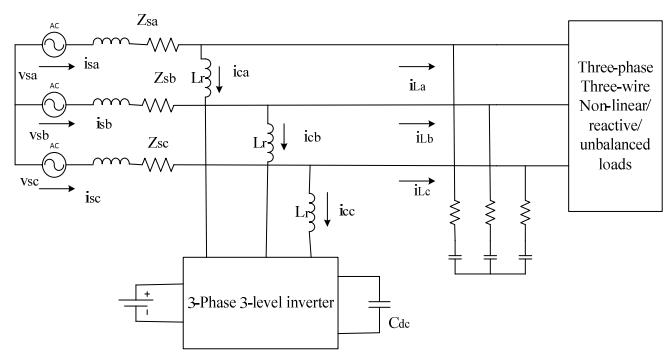

Fig1.Three-phase Three-wire

\subsection{Three-Phase Four-Wire DSTATCOM}

Three-phase four-wire DSTATCOMs are used to improve the power quality in Three phases four-wire distribution systems. The other topologies of DSTATCOM for threephase four-wire system are for the compensation of neutral current along with the power quality compensation in supply current. The number of power electronic switches is less here compared to three-phase three wire DSTATCOM. The figure represents the threephase voltages $\mathrm{Vsa}, \mathrm{Vsb}$, and Vsc and corresponding currents isa,isb and isc connected to Non-linear unbalanced load. The corresponding reactive currents are iLa, iLb, and iLc. Due to the main consideration of switching frequency and ripple current, the interfacing inductor is selected and the design of the DC bus capacitor on the energy storage capacity needed during transient conditions.[6]

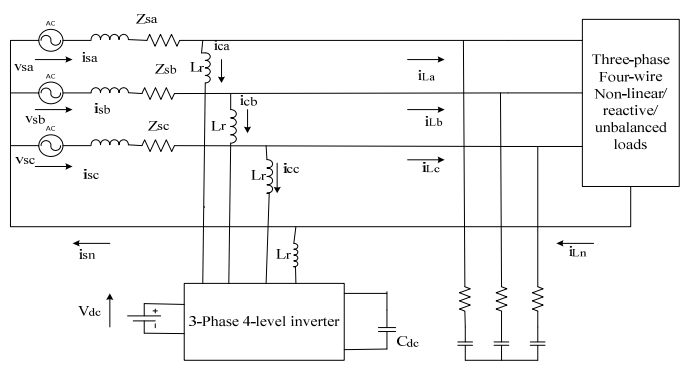

Fig 2. Three-phase four-wire

\section{CONTROL ALGORITHMS}

The performance of the DSTATCOM depends on the control algorithm i.e. the extraction of the current components. For this principle, there are many control schemes which are reported in the literature and some of these are Instantaneous reactive power theory (IRP), Synchronous Reference frame theory (SRF), Sliding mode controller(SMC), Model predictive controller(MPC), and Adaptive Neuro-fuzzy inference system(ANFIS). DSTATCOM provides the reactive power compensation in the load and as a result, the source current remains at unity power factor (UPF). Since just real power is being provided by the source, load adjusting is accomplished by making the source reference current adjusted. The reference source current used to choose the exchanging of the DSTATCOM has a genuine crucial recurrence part of the heap current which is being extricated by these procedures. The main objective of any control algorithm is that it should have a fast response, be flexible, and be easy to implement.[7]

\subsection{Synchronous Reference frame theory}

Synchronous Reference frame theory is used in threephase systems, which is one of the most popular PLL methods but it does not supply the individual values of phase, frequency, and amplitude. It will generally only average values. The main purpose of this method is to identify the voltage amplitude and frequency at a point of common coupling between the inverter. SRF theory is based on the transformation of currents in a synchronously rotating $d-q$ frame. Voltage signals are proposed by a phase-locked loop (PLL) to generate unit voltage templates (sine and cosine signals). [8]

Current signals are transformed to $\mathrm{d}-\mathrm{q}$ frame, whereas these signals are filtered and transformed back to the a-bc frame. This control technique is based on the extraction of the current component in phase with the unit voltage template. The reference source current is used to decide the switching of DSTATCOM has two components. One is the real fundamental frequency component of the load current, which is being extracted using the SRF theory. The SRF controller extracts de quantities by a low-pass filter, therefore, the non-dc quantities (harmonics) are separated from the reference signal.

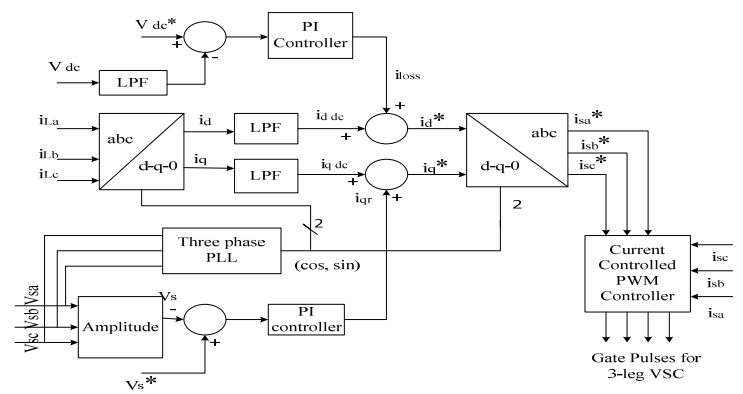

Fig3. SRF based controller

The Synchronous reference frame theory is based on the transformation of the currents in a synchronously rotating $\mathrm{d}-\mathrm{q}$ frame. If $\theta$ is the transformation angle, then the currents conversion from $\alpha-\beta$ to $\mathrm{d}-\mathrm{q}$ frame is defined as

$$
\left[\begin{array}{l}
i_{d} \\
i_{q}
\end{array}\right]=\left[\begin{array}{cc}
\operatorname{Cos} \theta & \operatorname{Sin} \theta \\
-\operatorname{Sin} \theta & \operatorname{Cos} \theta
\end{array}\right]\left[\begin{array}{l}
i_{\alpha} \\
i_{\beta}
\end{array}\right]
$$

The extracted DC components $i_{\text {ddc }}$ and $i_{\text {qdc }}$ are changed back into $\alpha-\beta$ frame as shown below

$\left[\begin{array}{l}i_{\alpha d c} \\ i_{\beta d c}\end{array}\right]=\left[\begin{array}{cc}\operatorname{Cos} \theta & \operatorname{Sin} \theta \\ -\operatorname{Sin} \theta & \operatorname{Cos} \theta\end{array}\right]\left[\begin{array}{l}i_{d d c} \\ i_{q d c}\end{array}\right]$ 
In this paper [9] proposed three-phase three-wire DSTATCOM for power quality improvement. The threeleg VSC-based DSTATCOM is controlled to mitigate reactive power, harmonic current, and unbalances in the load. This control technique extracts reference currents and also generates gate pulses for IGBT switches by PWM technique. So under varying load conditions DC bus controller regulates the DC bus voltage.

This paper [10] proposed a three-phase, four-wire, fourleg Voltage source inverter based on DSTATCOM. The DSTATCOM is worked in current-controlled mode by an appropriate control methodology, which infuses repaying current to accomplish symphonious pay, load adjusting, power factor rectification, and neutral current elimination. The four-leg compensator geography is constrained by coordinated reference frame (SRF) based control calculation. A sinusoidal PWM is used to produce triggering pulses for the inverter switches. The simulation results convey a low THD and a perfect compensation.

The paper proposes [11]a closed-loop control for the converter circuit by producing improved PWM beats that drive the converter switches. The shut circle control is based on Synchronous Reference Frame (SRF) hypothesis where a DC voltage can be utilized as a reference to control the AC voltage. The proposed paper contains a plan and reenactment of SRF based control for shut circle control of DC to AC transformation and age of upgraded PWM signals utilizing PSIM and MATLAB.

\subsection{Instantaneous Reactive power Theory}

Instantaneous reactive power theory has been initially proposed by Akagi in 1983. The hypothesis is based on the conversion of three-phase quantities to two-phase quantities in $\alpha-\beta$ frame and the estimate of instantaneous active and reactive power in this frame [12]. In IRP method real and reactive power components are required. This control algorithm is utilized to assess reference signals and with the assistance of reference signals heartbeats will be delivered and these heartbeats utilized for exchanging. By utilizing Clarke change, 3-stage signals are changed over to 2-stage segments, and these 2stage current and voltage segments are utilized to appraise P\&Q segments. This proposed algorithm have three-phase load currents and three-phase load voltages are coupled at the point of common coupling [13]-[15]

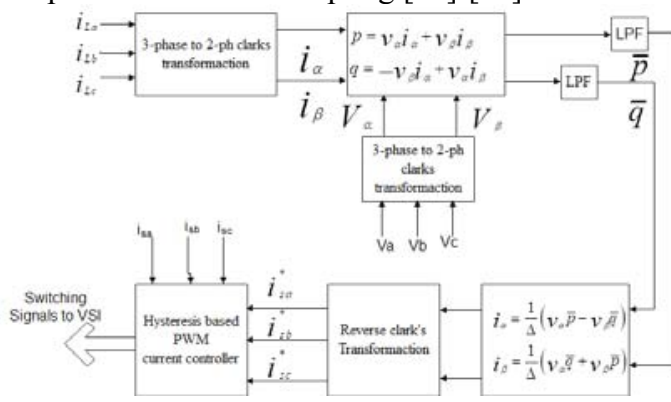

Fig 4. Instantaneous Reactive power Theory

In this strategy, the three-stage load current will Clarke changed, and three-stage voltages at the reason behind normal coupling (PCC) likewise Clarke changed. From these two qualities, genuine and receptive forces are assessed. Because of this Clarke change sign can be sifted rapidly and reference current qualities assessed[17]. These reference signals convert back into three-stage esteems utilizing opposite Clarke change. This reference esteems contrasted and the DSTATCOM infused flows then that blunder will be given to the hysteresis band PWM current regulator which will produce fitting heartbeats as per the heap variety. the system voltages are given as[18]-[19]

$$
\begin{aligned}
& v_{a}=V_{m} \operatorname{Sin}(\omega t) \\
& v_{b}=V_{m} \operatorname{Sin}(\omega t-120) \\
& v_{c}=V_{m} \operatorname{Sin}(\omega t-240)
\end{aligned}
$$

And respective load currents are given as

$$
\begin{aligned}
i_{L a} & =\sum I_{L a n} \sin \left\{n(\omega t)-\theta_{a n}\right\} \\
i_{L b} & =\sum I_{L b n} \sin \left\{n(\omega t-120)-\theta_{b n}\right\} \\
i_{L c} & =\sum I_{L c n} \sin \left\{n(\omega t-240)-\theta_{c n}\right\}
\end{aligned}
$$

These phasors can easily be transformed into $\alpha-\beta$ coordinates as follows

$$
\begin{aligned}
& {\left[\begin{array}{l}
v_{a} \\
v_{b}
\end{array}\right]=\sqrt{\frac{2}{3}}\left[\begin{array}{ccc}
1 & \frac{-1}{2} & \frac{-1}{2} \\
0 & \frac{\sqrt{3}}{2} & \frac{-\sqrt{3}}{2}
\end{array}\right]\left[\begin{array}{l}
v_{a} \\
v_{b} \\
v_{c}
\end{array}\right]} \\
& {\left[\begin{array}{l}
i_{\alpha} \\
i_{\beta}
\end{array}\right]=\sqrt{\frac{2}{3}}\left[\begin{array}{ccc}
1 & \frac{-1}{2} & \frac{-1}{2} \\
0 & \frac{\sqrt{3}}{2} & \frac{-\sqrt{3}}{2}
\end{array}\right]\left[\begin{array}{l}
i_{a} \\
i_{b} \\
i_{c}
\end{array}\right]}
\end{aligned}
$$

Where $\alpha$ and $\beta$ axes are the orthogonal coordinates. The conventional instantaneous power on the three-phase circuit can be defined as

$$
p=v_{a} i_{a}+v_{\beta} i_{\beta}
$$

Where $\mathrm{p}$ is equal to the conventional equation

$$
p=v_{a} i_{a}+v_{b} i_{b}+v_{c} i_{c}
$$

Similarly, the instantaneous reactive power is defined as

$$
q=-v_{\beta} i_{\alpha}+v_{\alpha} i_{\beta}
$$

Therefore in the matrix form, the instantaneous real and reactive powers are given as

$$
\left[\begin{array}{l}
p \\
q
\end{array}\right]=\left[\begin{array}{cc}
v_{\alpha} & v_{\beta} \\
-v_{\beta} & v_{\alpha}
\end{array}\right]\left[\begin{array}{l}
i_{\alpha} \\
i_{\beta}
\end{array}\right]
$$

The $\alpha-\beta$ currents can be obtained as

$$
\begin{array}{r}
{\left[\begin{array}{c}
i_{\alpha} \\
i_{\beta}
\end{array}\right]=\frac{1}{\Delta}\left[\begin{array}{cc}
v_{\alpha} & -v_{\beta} \\
v_{\beta} & v_{\alpha}
\end{array}\right]\left[\begin{array}{l}
p \\
q
\end{array}\right]} \\
\text { Where } \Delta=v_{\alpha}{ }^{2}+v_{\beta}{ }^{2}
\end{array}
$$


Therefore the reference source currents $i_{s \alpha}^{*}$ and $i_{s \beta}^{*}$ in $\alpha-\beta$ coordinate are expressed as

$$
\left[\begin{array}{l}
i_{s \alpha}^{*} \\
i_{s \beta}^{*}
\end{array}\right]=\frac{1}{\Delta}\left[\begin{array}{cc}
v_{a} & -v_{\beta} \\
v_{\beta} & v_{\alpha}
\end{array}\right]\left[\begin{array}{l}
\bar{p} \\
0
\end{array}\right]
$$

These currents can be changed in a-b-c quantities to find the reference currents in $a-b-c$ coordinate.

$$
\left[\begin{array}{l}
i_{s a}^{*} \\
i_{s b}^{*} \\
i_{s c}^{*}
\end{array}\right]=\sqrt{\frac{2}{3}}\left[\begin{array}{ccc}
\frac{1}{\sqrt{2}} & 1 & 0 \\
\frac{1}{\sqrt{2}} & \frac{-1}{2} & \frac{\sqrt{3}}{2} \\
\frac{1}{\sqrt{2}} & \frac{-1}{2} & \frac{-\sqrt{3}}{2}
\end{array}\right]\left[\begin{array}{l}
i_{0} \\
i_{\alpha} \\
i_{\beta}
\end{array}\right]
$$

This paper [20] discussed the modeling and design of Instantaneous Reactive power theory intended for control of DSTATCOM. Conservative IRPT is in the form of complete harmonic elimination is discussed and modeled. To regulate the voltage, improve power factor, reduce harmonics in source current, and also offered load balancing by connecting compensator in the system. The presentation of DSTATCOM utilizing these methodologies is tried and checked in both Power Factor Correction (PFC) mode and Zero Voltage Regulation (ZVR) mode for both ideal (sinusoidal) and reasonable (non-sinusoidal) voltages in transference structure.

This paper [21] discussed the performance of different active power filter (APF) control techniques resulting from five formulations of the instantaneous power theory. A comprehensive study of unbalanced nonlinear load in three-phase supply voltage conditions has been carried out. Only factorial and d-q formulations are achieved to obtain a null distortion in all of the cases.

\subsection{Model predictive control}

Model Predictive Control (MPC) is a very popular current control algorithm for controlling Power quality problems and also having fast-transient response. In addition to this, DSTATCOM is also used to maintain the load voltage at 1 p.u during voltage swells/sags. Shunt active power filters are used in each phase to improve the PCC voltage, which makes the system more difficult to control [22]. The system performance is virtual for load step changes and voltage sag conditions. In current control using conventional MPC, the difference between the reference and actual DSTATCOM currents is produced as a cost function (current error) and its value is calculated for each available switching state.[23]

DSTATCOM topologies, the cost function will also consist of the neutral current term along with phase currents, if the output voltage at each leg of the inverter is measured concerning the negative DC. One of the most important advantages of MPC is to control the flexibility of different variables, with constraints and additional system requirements, those are reactive power, commonmode voltages, switching losses, voltage unbalances, etc.
So this can lead to improving the system performance, efficiency, and safety to meet the IEEE standards. [24][25]

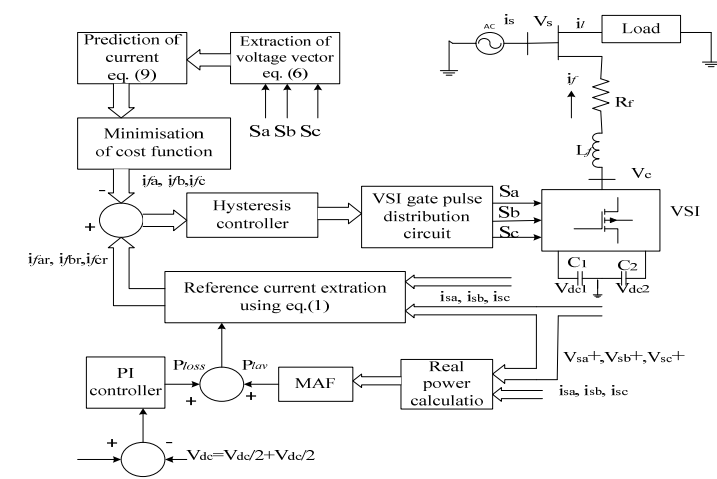

Fig 5. Model Predictive Control diagram

This paper [26] proposed a single-phase five-level rectifier with commonly coupled inductors. A single vector finite control set model predictive control (FCSMPC) algorithm is used to overcome the problems of a varied switching frequency. The FCS-MPC is used to eliminate the delay error and also reduced total harmonic distortion. The present used control algorithm has the advantages of fixed frequency, small calculation time, and small current steady-state error.

This paper [27] proposed a sophisticated control technique, consisting of a model predictive voltage control(MPVC) and a model predictive power control(MPPC), for interlinking converters. The flexible reactive power is injected into the main grid for grid support according to the voltage variation level. To ensure the power balance within the system, the energy management system (EMS) is considered the intermittent nature of the PV and load profile.

\subsection{Sliding Mode Controller}

The sliding mode controller is applied in the current control of the DSTATCOM, to regulate the voltage and also compensated the harmonics in load currents. The SM control technique is based on the development of a discontinuous control signal that drives the system states to the desired values[28]. To achieve this, two steps are required: the design of sliding surfaces that, when the scheme is in the sliding condition, follow the references correctly, and the design of a control law that guarantees the continuation of the sliding modes in the system. The three supply currents are sinusoidal and in phase with the supply voltages thereby unity power factor is achieved. In normal operations, due to its robustness properties, sliding mode controllers have two major design difficulties in the design of a control technique. 1) The system is highly nonlinear and 2) the performance of the system depends strongly on the knowledge of the loads nearby the DSTATCOM.[29]-[31] 


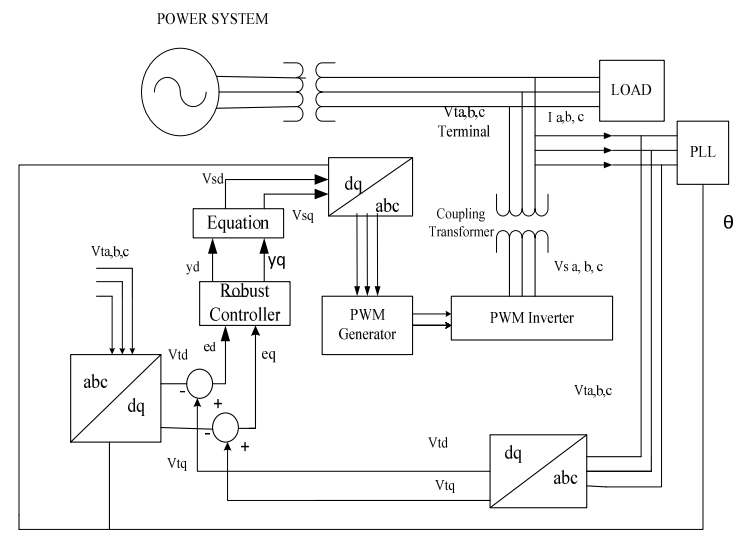

Fig 6.Sliding Model Control diagram

The in-phase components of unit vectors are calculated from the PCC voltages $\left(\mathrm{v}_{\mathrm{a}}, \mathrm{v}_{\mathrm{b}}\right.$ and $\left.\mathrm{v}_{\mathrm{c}}\right)$

The direct amplitude of PCC is estimated as,

$$
V t=\sqrt{2\left(v_{a}^{2}+v_{b}^{2}+v_{c}^{2}\right) / 3}
$$

The in-phase components of unit templates are computed as,

$$
\begin{aligned}
& u_{s a p}=\frac{v_{a}}{V_{t}} \\
& u_{s b p}=\frac{v_{b}}{V_{t}} \\
& u_{s c p}=\frac{v_{c}}{V_{t}}
\end{aligned}
$$

In this paper [32] proposed Switching Schemes of the sliding mode controller are analyzed and designed in the Frequency domain. In power distribution systems DSTATCOM in voltage control mode is investigated. The Two-level and three-level voltage source inverters are also described. The DSTATCOM improves the Total harmonic distortion (THD) and also controls the PCC voltage against the non-linearity in Load current.

In this paper proposed [33] Hysteresis and PWM current controllers are analyzed, designed and compared for PI as well as sliding mode controllers. Under variable load conditions, we performed the satisfactory operation of DSTATCOM acting as a shunt compensator. Hysteresis and PWM controllers are designed to obtain the switching logic operations for DSTATCOM. The performance of PI and SMC controllers is compared under steady-state conditions but varies under dynamic load changes.

This paper [34] proposed robust control of DSTATCOM which is controlled as a voltage source inverter with pulse width modulation. Sliding mode controller is an essential robust control approach. The simulation results showed that the ability of the sliding mode controller gave a better performance at all operating points with different types of load. An integrated approach for sliding mode controller to control the DSTATCOM is discussed. The proposed controller is used to overcome the uncertainties in the load and the loading conditions, therefore a robust controller can be achieved.

\subsection{Adaptive Neuro-Fuzzy Interference System}

To moderate the current related Power quality issues executed a control method based on the Adaptive Neuro fluffy derivation framework least mean square (ANFISLMS) for a three-stage conveyance static compensator (DSTATCOM). This calculation is shown for different elements of DSTATCOM, for example, solidarity power factor, load adjusting, music remuneration and voltage guideline. The key dynamic and receptive force segments from non-sinusoidal burden flows are assessed to reference supply flows from ANFIS-LMS based control calculation. The VSC comprises six protected entryway bipolar semiconductors (IGBTs) switches against equal diodes. The non-direct burden is displayed with an uncontrolled rectifier series R-L branch. The DSTATCOM is associated at PCC with the assistance of interfacing inductors (Lf), associated with channel compensator flows.[35]

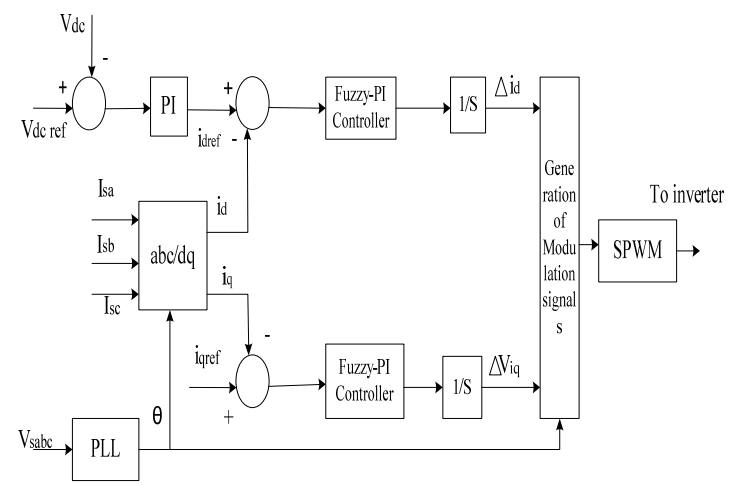

Fig7. Fuzzy-PI Current Controlled D-STATCOM

High exchanging recurrence parts produced by IGBTs are wiped out by resistive-capacitive (Rf-Cf) swell channels An amplitude of PCC voltage $(\mathrm{Vt})$ is given as

$$
V_{t}=\sqrt{\frac{2\left(V_{s a}^{2}+V_{s b}^{2}+V_{s c}^{2}\right)}{3}}
$$

where Vsa,Vsb and Vsc are the sensed PCC phase voltages.

In-phase unit templates of PCC Voltages, and are derived as,

$$
u_{p a}=\frac{V_{s a}}{V_{t}}, u_{p b}=\frac{V_{s b}}{V_{t}} \text { and } u_{p c}=\frac{V_{s c}}{V_{t}}
$$

The Proposed [36] control technique for DSTATCOM is compared with fixed step LMS and variable step LMS (VSLMS). The extracted weight converges closer and achieves constant value in the case of ANFIS-LMS, whereas it oscillates the mean value in the case of LMS and VSLMS control algorithms. The implementation of DSTATCOM using ANFIS-LMS based control is acceptable for PFC and voltage regulation modes under varying load conditions.

In this paper [37] proposed reduction of Low-Frequency Oscillation with STATCOM Based Fuzzy Logic Controller and Adaptive Neuro-Fuzzy Inference System 
Controller. Low-frequency oscillations (LFO) are an incessant hurtful marvel which increments the danger of unsteadiness for the force framework. They bind the consistent state power move limits, which accordingly changes functional framework financial matters and security. The Static coordinated Compensator (STATCOM) is one of the significant FACTS gadgets that can be utilized for dynamic remuneration of force frameworks to give voltage backing and steadiness improvement. In this paper, two novel control techniques for STATCOM have been examined and analyzed.

\subsection{Artificial Intelligence Based Controllers}

The control technique proposed for the DSTATCOM is a neural network-based one cycle control (OCC). This control technique includes neural organization block, advanced circuits and straight components, which dispenses with the sensors needed for detecting the load current and coupling inductor current withstanding the multiplier utilized in the traditional technique. The computation of symphonious and receptive flows for the reference current age is moreover wiped out, subsequently limiting the intricacy in the control procedure. The control procedure mitigates symphonious/responsive flows, guarantees adjusted and sinusoidal source current from the stock mains that are almost in stage with the supply voltage remunerates impartial current and keeps up with voltage across the capacitor under lopsided source and load conditions. The presentation of the DSTATCOM with the proposed fake neural organization (ANN) regulators are approved and explored through reproductions utilizing Matlab programming. The reenactment results demonstrate the viability of the proposed neural organization-based control procedure under fluctuating source and burden conditions.[38]

The vast majority of the business, private, official and IT industry structures are unequal nonlinear/direct loads associated with the three-stage four-wire (3P4W) conveyance framework. These loads are the reason for the enormous flow of neutral current having both fundamental and harmonic currents that create an overload on neutral conductors. Uneven nonlinear/straight loads associated with the 3P4W dissemination framework make the utility side have lower power factor, diminished energy proficiency, low force dealing with limit, furthermore, makes weak unsettling influences to the apparatuses associated with the appropriation framework. The practical answer for killing the force quality issues is latent and dynamic channels. The innovative work in the space of force gadgets demonstrates that dynamic force channels are better than latent channels because of the clear benefits like less reaction time, minimized size, better exhibitions, and so on.[39]

\subsubsection{ANN algorithm}

The distribution system has poor power quality because of the inadequate reactive power during the steady as well as the dynamic state. These issues generally emerge because of the presence of responsive and uneven loads. A VSC DSTATCOM gives a strong and effective technique of giving shunt remuneration in a line that can assist with upgrading the force quality. Different control strategies are accessible to infer the reference flows for the DSTATCOM like the coordinated reference outline theory (SRFT). The ANN and ANFIS based techniques are capable to decide and show the non-direct frameworks and can give a superior source current waveform and subsequently better force quality.[40]

In this paper, the SRFT method is compared to ANN and ANFIS based methods. The ANN-based control method is efficient and viable as it can identify as well as a model such non-linear systems. However, the ANFIS based has more efficiency as compared to the ANN-based method in giving a better source current waveform. The comparative results of ANN and ANFIS are analyzed and it is found that ANFIS gives superior performance when compared to ANN.

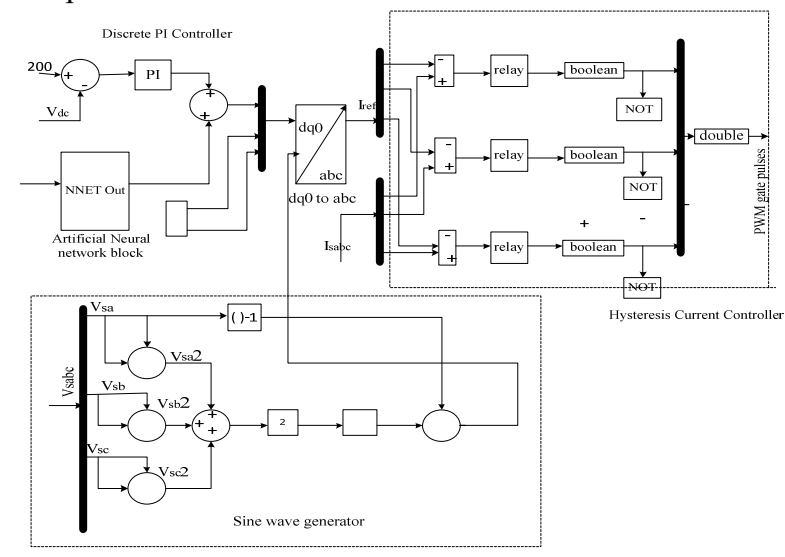

Fig.8 Control diagram of ANN algorithm

The performance of the network is analyzed by its mean square error (MSE). Its equation is as follows

$E_{m s e}=\sum_{K=1}^{N}=\frac{1}{2}\left[x_{f i}-x_{o i}\right]^{2}$

\subsubsection{ANFIS algorithm}

Adaptive Neuro-Fuzzy Inference System (ANFIS) is a group of counterfeit neural organizations which are functionally identical to the induction frameworks and combine non-straight and versatile, non-time invariant problem-solving characteristics of fake neural organizations with the important ideas of general reasoning and investigation of information as given by the fluffy set hypothesis. Their general advantage over ANN is that ANFIS presents an altogether better capacity to learn. [41] 


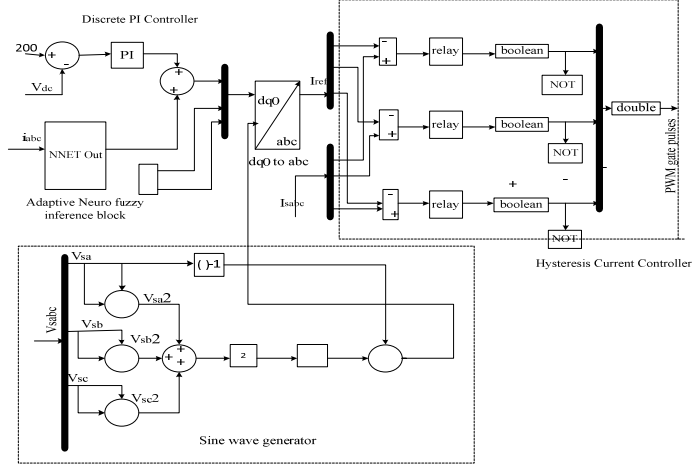

Fig 9.The control diagram of the ANFIS algorithm

It is further split into five layers as displayed in Fig. 5. Layer 1 is the info layer that takes three data sources that are the three-stage load flows and sends the contribution to layer 2 which performs the course of fuzzification by making fresh qualities fluffy. Layer 3 characterizes the layer which matches yield to enter. Layer 4 characterizes the standardization layer which is utilized to measure the terminating strength of standardization for a specific given standard.[42]

\subsection{3 self-tuning PI controller}

Increasing power electronics technologies convert a customary power system to be more brilliant and efficient. One use of these innovations is an appropriation static compensator (DSTATCOM) identified with An adaptable exchanging current transmission framework (FACTS). It's a shunt associated with the circulation framework at the purpose in like manner coupling (PCC) used to oversee and control the receptive force in request to further develop power quality (PQ) issues such voltage profile at PCC. This paper proposed another procedure for tuning regulator gains of DSTATCOM dependent on halfbreed molecule swarm advancement and counterfeit neural organizations (PSO-ANNs). The results of the simulation show the predominance, what's more, the strength of the proposed procedure of DSTATCOM to further develop voltage profile in the conveyance power framework.[43]

The capacity of DSTATCOM under defended conditions is to infuse the necessary responsive current to the load. DSTATCOM infuses these currents by utilizing PI regulator in its control procedure conspire as displayed in Fig. The output voltages for VSI are constrained by the PWM which is identified with Modulation Index (MI) and stage heavenly messenger $\alpha$. The necessary control factors are produced by the movable tuned PI regulator in the DSTATCOM plot.[44]

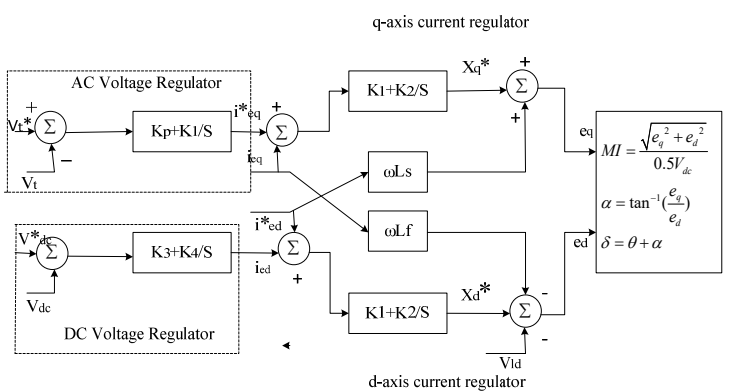

Fig.10 Self-Tuning PI Controller

DSTATCOM operation is based on the fact that the real and reactive power can be adjusted by the voltage magnitude of the inverter ( $\mathrm{Vc}$ ) and the angle difference between the bus and the inverter output $(\alpha)$. The equations for active and reactive power compensation are given as follows

$$
\begin{aligned}
& P=\frac{V_{p c c} V_{c} \sin \alpha}{X} \\
& Q=\frac{V_{p c c}\left(V_{p c c}-V_{c} \cos \alpha\right.}{X}
\end{aligned}
$$

Where $\mathrm{P}=$ Active power

$\mathrm{Q}=$ Reactive power

$$
\mathrm{Vc}=\text { Inverter voltage }
$$

$\mathrm{Vpcc}=$ Voltage at the point of common coupling $\alpha=$ Angle of Vpcc concerning Vc

$\mathrm{X}=$ Reactance of the branch and the transformer

The three-phase load voltages may be written as

$$
\left[\begin{array}{c}
v_{l a} \\
v_{l b} \\
v_{l c}
\end{array}\right]=R_{l}\left[\begin{array}{l}
i_{l a} \\
i_{l b} \\
i_{l c}
\end{array}\right]+L_{l} \frac{d}{d t}\left[\begin{array}{l}
i_{l a} \\
i_{l b} \\
i_{l c}
\end{array}\right]
$$

The load is assumed to be balanced, the park transformation is used to convert three phase system in to two phase dq system.

The park transformation is given as

$T=\frac{2}{3}\left[\begin{array}{ccc}\cos \theta & \cos (\theta-2 \pi / 3) & \cos (\theta+2 \pi / 3) \\ -\sin \theta & -\sin (\theta-2 \pi / 3) & -\sin (\theta+2 \pi / 3) \\ \frac{1}{2} & \frac{1}{2} & \frac{1}{2}\end{array}\right]$

Rotating reference frame equation as follows

$$
\begin{gathered}
{\left[\begin{array}{l}
v_{l d} \\
v_{l q}
\end{array}\right]=R_{t}\left[\begin{array}{l}
i_{l d} \\
i_{l q}
\end{array}\right]+L_{l} \frac{d}{d t}\left[\begin{array}{l}
i_{l d} \\
i_{l q}
\end{array}\right]+L_{l}\left[\begin{array}{cc}
\theta & -\omega \\
\omega & \theta
\end{array}\right]\left[\begin{array}{l}
i_{l d} \\
i_{l q}
\end{array}\right]} \\
\text { Where } \theta=\tan ^{-1}\left(\frac{v_{l q}}{v_{l d}}\right)
\end{gathered}
$$

3.6.4 ANN-based artificial neural network one cycle control (OCC)

The proposed control procedure produces exchanging signals for the DSTATCOM by utilizing a neural 
organization block, an integrator with reset, and advanced and direct parts. A different neural organization regulator is additionally executed for the single-stage APF to moderate the nonpartisan current under lopsided burden conditions. The proposed control procedure is liked for modern applications due to consistent exchanging recurrence and nonattendance of reference current computation in any event, when the stock voltage is twisted or potentially uneven with unequal direct/nonlinear loads. Two unique ANN regulators are proposed in this calculation to separate the force misfortune in the inverter what's more, interfacing inductor, consequently keeping up the DC transport capacitor voltage to its reference esteem by redressing the force misfortune; and to create exchanging signals for single stage APF for the moderation of nonpartisan current unbalanced load conditions.[45]-[47]

In the proposed neural organization-based control system, the control circuit for the DSTATCOM is planned as two free parts, that is, ANN-based control technique for three legs VSC APF and ANN-based reference current generation for neutral current mitigation, for better adaptability of activity.[48]

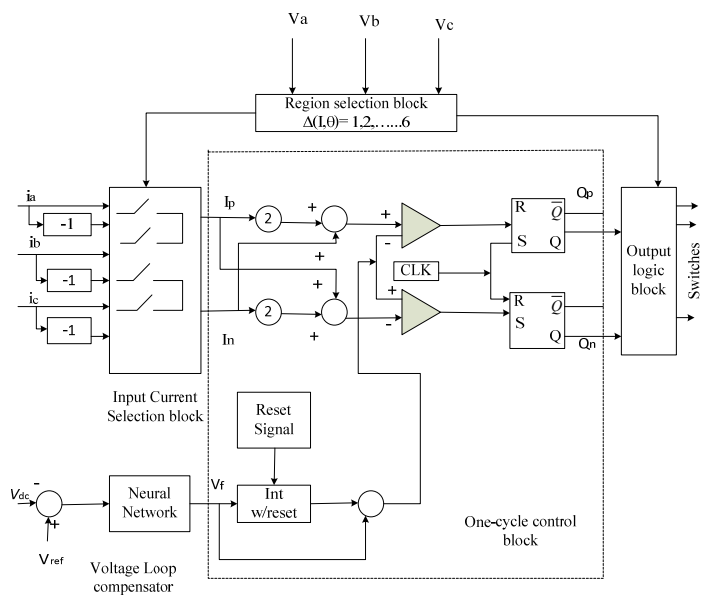

Fig 11.ANN-based OCC for three legs VSC APF

The steady-state relationship between $\mathrm{AC}$ voltage $\mathrm{Vs}$ and output DC voltage Vdc is given as

$$
\begin{array}{r}
K(d) V_{d c}=V_{s} \\
\text { Where } V_{s}=\left[\begin{array}{c}
V_{s a} \\
V_{s b} \\
V_{s c}
\end{array}\right] \\
d=\left[\begin{array}{l}
d_{a n} \\
d_{b n} \\
d_{c n}
\end{array}\right]
\end{array}
$$

is the $\mathrm{AC}$ source

voltage vector

$\mathrm{d}$ is the duty ratio vector

$$
\mathrm{K}(\mathrm{d})=\mathrm{A}+\mathrm{Bd}
$$

Where $\mathrm{A}$ and $\mathrm{B}$ are linear matrices
The main aim of the control strategy is to attain unity power factor(UPF) in all three phases, which can be expressed as

$$
V_{s}=R_{c} I_{s}
$$

Where $R_{c}=\left[\begin{array}{c}I_{s a} \\ I_{s b} \\ I_{s c}\end{array}\right]$

Equating the above two equations

$$
R_{s} I_{s}=K(d) V_{f}
$$

Where Rs is the resistance of the current sensor and Vf is defined as

$$
V_{f}=R_{s} \frac{V_{d c}}{R_{c}}
$$

\subsubsection{AIS-based adaptive control strategy of a DSTATCOM}

Because of the acceptable exhibition, it is then executed on a stage comprising of a constant advanced test system (RTDS) and a computerized signal processor (DSP). The benefit of RTDS is that it can address the elements of a framework near a pragmatic framework. The effective force electronic exchanging gadgets are too reproduced so that it tends to be interfaced with a functional equipment framework any time. The tuning of the regulator boundaries utilizing PSO to display natural reaction just as the AIS-based control procedure to show versatile reaction is executed on a DSP interfaced to the RTDS.[49]-[50]

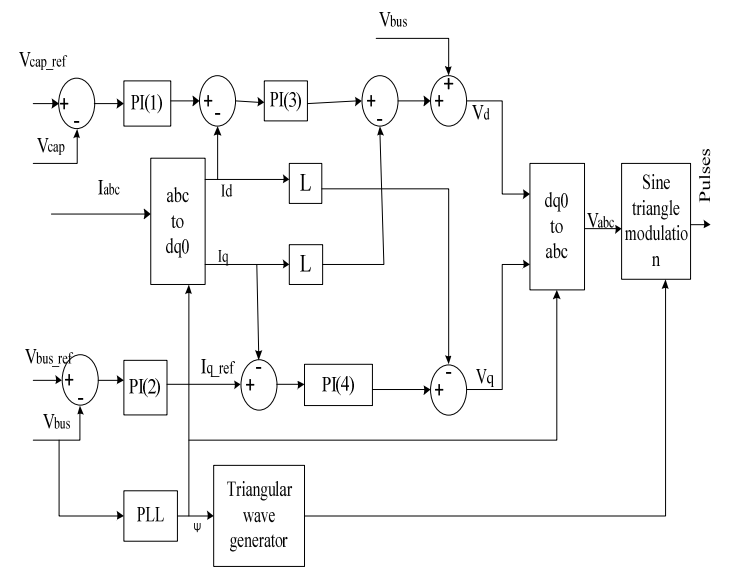

Fig12. DSTATCOM control structure for an RTDS implementation

The first type of control methodology is utilized for the MATLAB-based reenactment. Here, a door turn-off thyristor (GTO) based square-wave voltage-source converter (VSC) is used to produce the exchanging voltage from the dc transport. In this kind of inverter, the essential segment of the inverter yield voltage is relative to the dc transport voltage.[51]Along these lines, the control objective is to control Vdc according to the prerequisite. 
Additionally, the staging point ought to be kept up with so the air conditioner-created voltage is in stage with the transport voltage. The schematic graph of the control circuit is displayed in Fig [12]

The optimal values of the PI controller parameters are first tuned by PSO algorithm. The velocity and position of the $i$ th particle of d dimension is updated by the following equations[52]-[53]

$$
\begin{gathered}
v_{i d}(k+1)=w v_{i d}(k)+c_{1} \operatorname{rand}_{1}\left(x_{\text {pbest-id }}(k)\right. \\
\left.-x_{i d}(k)\right)+c_{2} \operatorname{rand}_{2}\left(x_{\text {gbest }-i d}(k)-x_{i d}(k)\right) \\
x_{i d}(k+1)=x_{i d}(k)+v_{i d}(k+1)
\end{gathered}
$$

Where $x_{i d}(k)$ and $x_{i d}(k+1)$ are the positions

$$
J=\sum_{k=1}^{T / \Delta t} \frac{1}{2}(\Delta v(k)+\Delta v(k+1)) \Delta t
$$

\begin{tabular}{|c|c|c|c|}
\hline S.No & $\begin{array}{l}\text { Control } \\
\text { algorithms }\end{array}$ & Advantages & Disadvantages \\
\hline 1 & $\begin{array}{l}\text { SRF } \\
\text { Theory }\end{array}$ & $\begin{array}{l}\text { 1.This method can be used to reduce the } \\
\text { harmonics and also for compensating the } \\
\text { reactive power. SRF employs mainly Clarkes } \\
\text { and reverses Clarks transformations [8] } \\
\text { 2. Better performance in achieving unity } \\
\text { power factor condition for both Linear and } \\
\text { Non-linear load }\end{array}$ & $\begin{array}{l}\text { The generation of voltage templates (sin and } \\
\text { cosine terms is crucial) } \\
\text { - PLL (phase-locked loop) is used generation of } \\
\text { templates. The operation of PLL is slow and } \\
\text { also imposes some of the amounts of delay in } \\
\text { computation [9] } \\
\text { - Effect of delay due to LPF used for filtering } \\
\text { signals in d- q frame } \\
\text { - Mathematical computations are more and not } \\
\text { suitable for 3-phase 4- wire systems. }\end{array}$ \\
\hline 2 & IRP Theory & $\begin{array}{l}\text { IRP theory having high Computational } \\
\text { Complexity, as it requires complex } \\
\text { transformation and also dealing with the } \\
\text { power components [12] }\end{array}$ & $\begin{array}{c}\text { - Delay in computation due to LPF used for } \\
\text { filtering power signals } \\
\text { - This theory uses volt signals to compute } \\
\text { instantaneous active and reactive powers if any } \\
\text { variations in supply voltage cause inaccurate } \\
\text { measurements[17] }\end{array}$ \\
\hline 3 & $\begin{array}{l}\text { Model } \\
\text { Predictive } \\
\text { Control }\end{array}$ & $\begin{array}{l}\text { 1. MPC of NNPC DSTATCOM is used to } \\
\text { compensate for the current related power } \\
\text { quality problems such as harmonic, reactive, } \\
\text { and neutral currents and also to maintain a } \\
\text { constant voltage across each flying } \\
\text { capacitor.[22] } \\
\text { 2. MPC algorithm is easy implementation, } \\
\text { providing a good dynamic and steady-state } \\
\text { response, and constraints can be easily added } \\
\text { to the cost function }\end{array}$ & $\begin{array}{l}\text { 1. Two additional constraints are included in the } \\
\text { cost function using weighting factors.[24] }\end{array}$ \\
\hline 4 & $\begin{array}{l}\text { Sliding } \\
\text { Mode } \\
\text { Controller }\end{array}$ & $\begin{array}{l}\text { 1. SMC is a variable structure control system } \\
\text { that increases the robustness of the system and } \\
\text { preserves stability under variations and } \\
\text { external disturbances } \\
\text { 2. sliding mode control[28] is capable of } \\
\text { harmonic elimination of source current and } \\
\text { successfully verified by the IEEE-519 } \\
\text { standard. }\end{array}$ & $\begin{array}{c}\text { 1. Due to resonance problems and fixed } \\
\text { compensation in these filters, custom power } \\
\text { devices are now available for mitigating power } \\
\text { quality concerns.[31] }\end{array}$ \\
\hline 5 & $\begin{array}{l}\text { ANFIS } \\
\text { algorithm }\end{array}$ & $\begin{array}{l}\text { 1. ANFIS-LMS based control algorithm is } \\
\text { found satisfactory under steady-state and } \\
\text { dynamic load conditions. } \\
\text { 2. This algorithm is verified for various } \\
\text { functions of DSTATCOM such as harmonics } \\
\text { compensation, unity power factor, load } \\
\text { balancing and voltage regulation.[35] }\end{array}$ & $\begin{array}{l}\text { 1. This control technique does not work well } \\
\text { under non-sinusoidal supply voltages.[37] }\end{array}$ \\
\hline 6 & $\begin{array}{l}\text { Artificial } \\
\text { Intelligence } \\
\text { Based } \\
\text { Controllers } \\
\end{array}$ & $\begin{array}{l}\text { 1. This is used for compensation of the } \\
\text { reactive power along with the current related } \\
\text { power quality issues that include harmonics. } \\
\text { 2. less response time, compact size }\end{array}$ & $\begin{array}{l}\text { 1. High cost of implementation } \\
\text { 2. lakhs of creativity }\end{array}$ \\
\hline
\end{tabular}

Table 1.Comparison of Control algorithms 


\section{CONCLUSION}

This paper reviewed DSTATCOM topologies and Control Techniques. Those topologies are three-phase three-wire and Three-phase four-wire and control techniques are Instantaneous Reactive power theory(IRP), Synchronous Reference Frame Theory(SRF), Model Predictive Control(MPC), Sliding mode control(SMC) and Adaptive Neurofuzzy interface systems(ANFIS). These control techniques are used to improve the power factor, Reactive power compensation, harmonic mitigation, load balancing in the power system.IRP and SRF control techniques have some drawbacks related to not robust control. SMC control technique had good dynamic performance and having robustness of the system against external conditions. The ANFIS algorithm has advantages in terms of fast convergence, less static error and fast learning of stepsize parameters. The MPC control algorithm contains two control parameters, one is to balance the current related power quality issues and the extra one is to maintain a constant voltage across the capacitors.

\section{References}

1. Montero, M. I. M., Cadaval, E. R., \& González, F. B. (2007).. IEEE Transactions on Power Electronics, 22,229-236.

2. Chenchireddy, Kalagotla, V. Jegathesan, and L. Ashok Kumar. Innovations in Electrical and Electronics Engineering (2020): 35-43.

3. Singh, B., Jayaprakash, P., Kothari, D. P., Chandra, A., \& Haddad, K. al. (2014). IEEE Transactions on Industrial Informatics, 10(2), 854-870

4. Venkata Krishna Reddy, M., Veni, K., \& Das, D. (n.d.). International Journal of Electrical and Electronics Engineering Research (IJEEER) Vol.1, Issue 2 149-171 Dec (2011)

5. Rohouma, W., Balog, R. S., Peerzada, A. A., \& Begovic, M. M. (2020). Renewable Energy, 145, 1449-1464

6. Ali, C., Fellah, M.-K., El, U. M., El, B., de Bordj, I., Arréridj, B., Fouad, M., Benkhoris, F., Chebabhi, A., Fellah, M. K., Kessal, A., \& Fouad Benkhoris, M. (n.d.). $X X(X)$ (2011) $X$ - $X$

7. Singh, B., Jayaprakash, P., \& Kothari, D. P. (2011). International Journal of Electrical Power and Energy Systems, 33(5), 1109-1117

8. Sujono, Sudiharto, I., \& Qudsi, O. A. (2020). EECCIS 2020 - 2020 10th Electrical Power, Electronics, Communications, Controls, and Informatics Seminar, 65-70

9. Tejas Zaveri 1,Bhalja Bhavesh2 , and Naimish Zaveri3 2011 IEEE International Electric
Machines \& Drives Conference (IEMDC): IEMDC 11 : May 15-18, 2011

10. Chenchireddy, Kalagotla, V. Kumar, and Khammampati R. Sreejyothi. 2021 7th International Conference on Advanced Computing and Communication Systems (ICACCS). Vol. 1. IEEE, (2021)

11. Kumar, R. S. (n.d.) International Journal on Applications in Electrical and Electronics Engineering Volume 1 Issue 4, pp:1-6 April (2015)

12. Deepthi V. (n.d.) International journal of engineering research \& technology (ijert) volume 04, issue 05 (may 2015)

13. P. Venkata Kishore, Prof. S. Rama Reddy, IOSR Journal of Electrical and Electronics Engineering (IOSR- JEEE) e-ISSN: 2278-1676, p-ISSN:23203331, Volume 9, Issue 1 Ver. I PP 17-27 (Jan. 2014).

14. P. Kumar, India International Conference on Power Electronics 2010 pp. 1-4 (IICPE2010), (2011)

15. Ramakrishna, E., Bharath Kumar, P., Jaya Krishna, G., \& Sujatha, P. (2021). In Turkish Journal of Computer and Mathematics Education , Vol. 12, Issue 2.

16. Suresh, D., Sravanthi, G., \& Chander, R. (n.d.). E3S W eb of Conferences, 87,01013, (2019)

17. Herrera, R. S., \& Salmerón, P. (2009). IEEE Transactions on Industrial Electronics, 56(6), 2015-2022

18. Kamaladevi, K., \& Mohan Murali Krishna, N. (n.d.).International Journal of Technical Research and Applications Vol. 3.

19. Gairola, S., \& Chamoli, M. M. (n.d.) International journal of engineering research \& technology (ijert) volume $\mathbf{0 7}$, issue 07 (july 2018).

20. X. Kong, Y. Yuan, H. Huang and Y. Wang, 2015 5th International Conference on Electric Utility Deregulation and Restructuring and Power Technologies (DRPT), pp 2331-2336 (2015)

21. Sydu, Shabbier Ahmed, Kalagotla Chenchireddy, and Khammampati R. Sreejyothi. Available at SSRN 3852706 (2021).

22. Darabian, M., Jalilvand, A., Ashouri, A., \& Bagheri, A. (2020). International Journal of Electrical Power and Energy Systems, 120.

23. Geyer, T. (2011). IEEE Transactions on Power Electronics, 26(10), 2804-2816. 
24. Kouro, S., Cortés, P., Vargas, R., Ammann, U., \& Rodríguez, J. (2009). IEEE Transactions on Industrial Electronics, 56(6), 1826-1838

25. Calle-Prado, A., Alepuz, S., Bordonau, J., Nicolas-Apruzzese, J., Cortés, P., \& Rodriguez, J. (2015). IEEE Transactions on Industrial Electronics, 62(3), 1503-1514.

26. Zhu, Y., Yue, H., Zhao, H., \& Xu, H. Energies, 13(9), (2020).

27. Hu, J., Xu, Y., Cheng, K. W., \& Guerrero, J. M. (2018). Applied Energy, 221, 195-203

28. Shahgholian, G., \& Azimi, Z. Electronics (Switzerland), 5(3), (2016)

29. Ma, R., Han, Y., \& Pan, W. (2021). Energies, 14(2).

30. Halder, A., Pal, N., \& Mondal, D. (2020). Mathematics and Computers in Simulation, 177, 244-262

31. Hou, R., \& Li, C. P. (2012). Advanced Materials Research. 543-547

32. Gupta, R., \& Ghosh, A. (2006). IEEE Transactions on Circuits and Systems I: Regular Papers, 53(3), 662-676.

33. B. Singh, A. Adya, A. P. Mittal and J. R. P. Gupta, 2008 Joint International Conference on Power System Technology and IEEE Power India Conference, (2008)

34. A. Jain, A. Behal, X. Zhang, D. Dawson, and N. Mohan, IEEE Transactions on Control Systems Technology, vol. 12, pp. 827 - 842, Nov (2004).

35. Badoni, M., Singh, A., \& Singh, B. (2016).. IEEE Transactions on Industrial Informatics, 12(2), 483-492

36. P. Rao, M. L. Crow, and Z. Yang, IEEE Trans. Power Del., vol. 15, no. 4, pp. 1311-1317, Oct. (2000).

37. M. Mangaraj, A. K. Panda and T. Penthia, 2016 IEEE 6th International Conference on Power Systems (ICPS), 2016, pp. 1-5

38. Jayachandran, J., \& Sachithanandam, R. M (2015). Frontiers in

39. Mitra, P., \& Venayagamoorthy, G. K. (2010). IEEE Transactions on Power Electronics, 25(1), 95-104

40. Jain College of Engineering, Institute of Electrical and Electronics Engineers. Bangalore Section., \& Institute of Electrical and Electronics Engineers. (n.d.). 2020 International Conference for Emerging Technology (INCET) : Belgaum, India. Jun 5-7, 2020.

41. Soodi, H. A., \& Vural, A. M. (2018). STATCOM Computational Intelligence and Neuroscience, 2018.
42. Arockia Edwin Xavier, S., Venkatesh, P., \& Saravanan, M. (2013). Applied Soft Computing Journal, 13(4), 1750-1758

43. Chenchireddy, Kalagotla, and V. Jegathesan. Inventive Communication and Computational Technologies (2021): 961-971.

44. Jyothi, P., R Prakash, R. B., Srinivasa Varma, P., \& Author, C. (2020). Vol. 10, Issue 2.

45. Saafin, Z. A., Zaro, F., \& Jawadeh, M. (n.d.) Journal of Soft computing and artificial intelligence, JSCAI, 2(1) pp:41-55 (2021).

46. Garg, A., Pratap, R., Assistant, S., Bijli, H., \& Nigam, V.. ISSN : 2249-0868 Foundation of Computer Science FCS. In International Journal of Applied Information Systems (IJAIS) Vol. 6, Issue 1, (2013).

47. A Ayyappa Swamy and, P. A. P. (2020). International Journal for Modern Trends in Science and Technology, 8, 5-9

48. Rajkumar, C. v, \& Dattabhimaraju, S. P. (n.d.), International Journal of Engineering Research \& Technology (IJERT) Vol. 2 Issue 2, February2013 ISSN: 2278-0181

49. Nikzad, M., Farahani, S. S. S., \& Hemati, R. (2009). World Applied Sciences Journal, 7(11), $1428-1438$

50. S, S. J. (2015). IJIREEICE, 3(5), 150-158

51. Mohanraj, M. R., \& Prakash, R. (2019). International Journal of Recent Technology and Engineering, 8 Special Issue 11, 322-331

52. Singh, B., Sharma, N. K., \& Tiwari, A. N. (n.d.), 16th NATIONAL POWER SYSTEMS CONFERENCE, 15th-17th DECEMBER, (2010)

53. Zhihong Feng, Ven Kataramana Ajjarapu, and Dominic J. Maratukulam, IEEE Trans on Power Systems, Vol. 15, No.2, May (2000). 